\title{
FRANCISCO DE TERRAZAS
}

\author{
PO R
}

\section{SALVADOR'TOSCANO}

NO obstante que las noticias publicadas sobre Francisco de Terrazas -el primer poeta criollo de México- se han ampliado desde los tiempos de García Icazbalceta, todavía ignoramos la fecha y el lugar de su nacimiento. Fué hijo del conquistador del mismo nombre, a quien Bernal Díaz llama "personaje preminente" y mayordomo y compañero de Cortés; por su rama materna era hijo de doña Ana de Obregón, hija de la famosa Mari López de Obregón, a cuyo entierro acudieron setenta descendientes vestidos de loba, capuz y toca negra; igualmente, por lo mismo, fué primo del historiador Baltasar de Obregón.

García Icazbalceta hacia morir al padre de Terrazas en 1549 , siendo alcalde ordinario del municipio de México y, conjeturalmente, se le menciona como el autor de una Crónica de la expedición de Cortés a las Hibueras, que Muñoz Camargo llama Tratado de aire $y$ tierra. ${ }^{1}$ Nuestro

1 Diego Mnfiaz Camargo: Historia de Tlaxcala, p. 253. Mézico, 1892. Sin embargo, punto a homóninos de Terrazas debemos proceder con anma cantela: recientemente el Lic. Pedro López publico el testamento de un Francisco de Terrazas que anpuso el padre de auestro poeta, pero del texto $*$ desprenden conclusiones contra 
poeta, por lo mismo, debió nacer antes de 1549 , sin que hasta ahora podamos precisar el dato; sin embargo, el hecho de aparacer en 1564 contestando unas coplas a Eslava nos hace suponer que debió nacer algunos años antes de 1540 .

Ignoramos si Terrazas estuvo en Europa, aunque es más que probable, ya que se le menciona como poeta "toscano y latino". Sin embargo, su lírica italoclásica pudo derivarla de la definitiva influencia que hacia 1557 debió ejercer Gutierre de Cetina en México.

A la muerte de su padre lo substituyó como encomendero en parte de Tulancingo, en el Arzobispado de México, y en Igualtépec y Asuchila, en Oaxaca. Así se afirma en una Lista o reloción de pueblos formada en la segunda mitad del siglo $\mathrm{xvI}$ : "La mitad de Tulancingo -con sus 2527 tributarios_, en el Arzobispado de México, e la mitad de Igualtépec y Asuchiquizala - con sus 285 tributarios- en el Obispado de Guaxaca, fueron encomendados en Francisco de Terrazas, conquistador e primero tenedor, por cuya muerte sucedieron en Francisco de Terrazas, su hijo, e lo pasee." 2

Francisco de Terrazas debió morir poco antes de 1585, según se desprende de las palabras de Alonso de Zorita, autor español que para esa fecha escribia su Historia de la Nueva España, dato éste que ha escapado

rias. ya que alli se le menciona como criado al servicio de Martín Cortéa $y$ con 0610 un bijo "natural". (Revista del Centro de Eatudios Extremefios, t. X., cuad. III. Badajoz, 1936). Icazbalceta ya bizo, igualmente, notar $b$ presencia de otro homonimo que en 1570 aparece como vicario en el pueblo de Xicotepec. Tambikn debemon mencionar como an bomónimo o como nn dexcendiente del poeta, al Franciveo de Terrazan que en 1600. conforme a on manuscrito del Arzobispado de México que estadiare don Alberto María Carrefio, pedia profesión de monja para su hija Francice. (Joyas titeratias del siglo XVII encontradas en Mexico, p. 199. Mérico, 1915).

2 El dato lo confirman otras relaciones primitivas. Una de ellas es el informe del visitador Ovando en 1569 (Códice Franciscano. Pub. por J. G. Icazbalceta, p. 14. de la edicion de 1914). Otra ea Relación de Tepezpuko de 1581; en ella asienta que la mitad de Tulancingo estuvo encomendada a Terrazas y la otra mitad a Hernando Dávila, y eggún notz de Paso y Troncoso el padre de Terraza tuvo originariamente a Tulancingo totalmente en so encomienda, pero al separirsele 12 mitad a 1 trats de compensar con el pueblo de Igualtépec, en Oaxaca. (Papeles de Nueva Etpaña. Relaciones geogntficas de la diobesis de Mixico, t. IV, p. 295. Madrid, 1905). La importancia de la encomienda no debe panare por alto; no en vano ef arzobispo y virrey Moya de Conterme to cuñalaba como gran poeta $y$ "hombre de celjodad, axior de pueblos" (Icaza: Origenew ded teatro en Míxico. Boletín de le Real Ácadeanis Eopafiola, t. II. Madrid. 1915.) 
a todos los biógrafos del poeta y que merece, por lo mismo, trasladarae integro: "Francisco de Terrazas, vecino de México, hijo de uno de los conquistadores de aquellas tierras, donde tiene un muy buen repartimiento, comencé a escribir en metro de octava rima la conquista de la Nuena España; era hombre suficiente para ello y de buen juicio y que tenía muy buena habilidad para todo género de versos castellanos, y porgke wurio antes de la acabar, la prosigue Juan Gonzáles, clérigo capellán de la Iglesia Mayor de México, y que tiene habilidad y suficiencia para ello y que escribe y lleva el mismo estilo que Terrazas". 8

La época de más intensa actividad poética de Terrazas va de 1564 a 1584, año éste en que Cervantes lo elogiaba cumplidamente y en que, conforme hemos visto, debia haber muerto en la ciudad de México. En efecto, la primera alusión que se conoce acerca de Terrazas como poeta es en un proceso inquisitorial de 1564 , proceso que el Tribunal de la Fe siguiera por supuesto judaísmo a Juan Batutista Corvera; mencionándose allí a Eslava y a Terrazas como los autores de unas coplas sobre el Antiguo Testamento que parecieron sospechosas de heterodoxia; alli aparece Corvera aceptando ser el autor de algunas poesias que le fueran recogidas, pero negando la paternidad de las coplas que originaran el proceso y atribuyéndolas a Eslava y a Terrazas. La veracidad de Corvera en su atribución vino a confirmarla el hallazgo de otro proceso inquisitorial en que un cuñado de Terrazas, Sebastián Vázquez, para descargo de su conciencia entregó coplas iguales al tribunal de la Inquisición (1571). 4

En 1574 y en 1575 volvemos a encontrar a Terrazas envuelto en otro grave incidente originado por la rivalidad del arzobispo Moya y Contreras con el entonces virrey de México, rivalidad que culminó con el encarcelamiento de Eslava y de Terrazas, este último acusado de ser el autor

3 Alonso de Zorita: Historia de la Nueua España, t. I, p. 23. Madrid, 1909.

4 Estas poesias de circuntancias fueron por primera vez dadas a conocer por Alfonso Toro (Los Judios en la Nueva Españo, t. XX. pub. A. G. N. México, 1932, pp. 181-185). Sin embargo, annque el procesado Corvera afirmaba que Eslava y Terrazas erap ons autorea, ninguna conclusión ex desprendió del documento. Pero el ha1 lazgo povterior de otro proceso en 1571, abierto por un pariente de Texzazas, vino a comprobar la correcta atribución de Corvera: dicho proceso fué reproducido $y$ dado a conocer por Edmundo O'Gorman y trankcritas con- integridad y corrección las coNas de nacitica do poetas (Boletí del Archivo General de la Nación. t. XI, núm. 14. México). 
de un libelo que apareció fijado en la Catedral en contra de la persona del virrey. ${ }^{s}$

En 1577 se le encuentra figurando en una recopilación poética Flores de varia poesia, antologia que al parecer hiciera durante su estancia en México el poeta español Juan de la Cueva, seleccionando su material de poetas españoles y mexicanos (Cetina, Eslava, Terrazas, De la Cueva, etcétera.) ${ }^{\circ}$

Para esta época nuestro poeta debía encontrarse en la en la plenitud y para entonces debía trabajar en su poema épico octosilábico Nuevo Mundo y Conquista que le inspirara La Araucana de Ercilla. La muerte, como hemos visto, cortó esta promesa de Terrazas. En 1584 el poeta mereció el elogio del propio Cervantes, quien en una estrofa bien conocida de su Canto a Calíope, que figura en La Galatea, dice:

De la región antártica podría eternizar ingenios soberanos...

Francisco, el uno, de Terrazas tiene el nombre acá y allá tan conocido cuya vena caudal nueva Hipocrene ha dado al patrio venturoso nido...

La obra poética de Terrazas es sumamente escasa y apenas si nos autoriza a emitir juicios definitivos. García Icazbalceta llamaba a nuestro autor "honrada medianía", pero parecía referirse más bien al poeta épico que al lírico. En efecto, si juzgamos a Terrazas por sus sonetos y por los fragmentos líricos de su obra trunca, debemos convenir en el desinteresado elogio de Cervantes. Por otra parte no debemos olvidar que el

5 Jose Rojas Garcidueñas. El Teatro de Nueva España en el siglo XVI. Méx. 1935. p. 83.

6 Gallardo fué el primero en reproducir tres de los sonetos que en dicha antologia aparexen atribaidos a Terrazas (Ensajo de una Bibliozeca de Libros Raros v Curiosos, t. 1, Madrid, 1889): Icazbalceta que más tarde los volvió a reproducir, euprimió el regundo por "sobradamente libre". Otros dos sonetos más de dicha recopilación ban sido recientemente reproducidos. Los otros cuatro sonetos conocidos fueron deacubiertos por Pedro Henríquez Uré̃a (Nuevas poesias atribuídas a Terrazas. "Revista de Filologia Española", t. v, pp. 49-56. Madrid. 1918), fueron deccubierto en un cancionero manuacrito que fuera de la Biblioteca Propincial de Toledo $y$ que boy figum en la Biblioteca Nacional de Madrid. 
propio Icazbalceta situaba a nuestro poeta en la "buena escuela del siglo Xvi". 7

La obra conocida, sin embargo, por su escasez apenas si nos autoriza a conclusiones definitivas : algunas coplas circunstanciales, sonetos y octavas, de un poema épico sobre la conquista que no concluyera; dos respuestas a Eslava sobre una pregunta relativa a la interpretación del Antiguo Testamento. No sólo son obras de circunstancia sino de juventud, ya que debieron escribirse antes de 1564 ; nueve admirables sonetos líricos que se recogieron en recopilaciones del siglo xvi (Flores de varia poesia y Cancionero Manuscrito de Toledo). .Debe hacerse notar, sin embargo, que el más delicado de los poemas, como lo ha comprobado Antonio Castro Leal, no es sino una paráfrasis de un soneto de Camoens; aquel que dice: Dejad las hebras de oro . . ${ }^{8}$ nimerosos fragmentos en octavas rimas de un poema inconcluso, Nuevo Mundo y Conquista. Dicho poema por la muerte de Terrazas pretendió ser concluido, como hemos visto, por el capellán catedralicio Juan González; pero como en el manuscrito de Baltasar Dorantes -en alguna ocasión aparece testado el nombre de Terrazas y sobrepuesto el de un Arrázola-, la confusión acerca de la atribución correcta de todas las octavas parece todavía crecer más.

7 Joaquín Gatcia Icazbalceta: Francisco de Terrazas y otros poetas del siglo XVI. ("Memorias de la Academia Mexicana", t. II, pp. 357-425. México, 1880).

8 Antonio Castro Leal: Un soneto de Terrazas inspirado en Camoens. "Revista Mexicana de Literatura Mexicana". núm. 1. México. 1941.

9 Baltasar Dorantes de Carranza: Sumaria Relación de las Cosas de Ia Nueua Esparia . . Ed. del Museo Nacional de México. México, 1902. 